\title{
Življenje ob meji je nevarno in težko Skupnosti mrtvih, družbe živih: poznobronastodobno grobišče v Zavrču
}

\author{
Martina Blečić Kavur \\ UP FHŠ Oddelek za arheologijo in dediščino ter Inštitut za arheologijo in dediščino \\ martina.blecic.kavur@upr.si
}

\section{Uvod}

$\mathrm{V}$ zadnjih petindvajsetih letih je bilo $\mathrm{v}$ procesu izgradnje avtocestnega omrežja na področju vzhodne, osrednje in južne Slovenije odkrito večje število arheoloških najdišč $\mathrm{z}$ ostanki iz bronaste dobe, ki so temeljito dopolnili in hkrati spremenili naše poznavanje tega prazgodovinskega obdobja (Kavur 2007). Nekaj delnih objav je prehitevalo monografske objave posameznih najdišč in napovedovalo potencial tega, kar nas čaka (Črešnar 2010; 2011; Kavur 2011; 2012; Kerman 2011). Predvsem v zadnjem desetletju pa smo poleg katalogov dočakali tudi poskus izkoriščenja velike količine novih podatkov in sintetičnega združevanja interpretacij v kulturnozgodovinski pregled (Teržan in Črešnar 2014a), ki bi bil utemeljen na absolutni kronologiji (Črešnar 2009; Teržan in Črešnar 2014b). Doseženi rezultati so spremenili našo percepcijo preteklosti oziroma razumevanje vpetosti arheoloških najdišč, to je naselij in grobišč, v nekdanje pokrajine. Pokazalo se je, da je bilo v pokrajini neizmerno več sledi preteklih človeških delovanj, kot smo lahko domnevali tri desetletja prej ter, morda najpomembneje, da so se ljudje vedno znova vračali na prostore, katerim v tradicionalnem sklepanju o interakciji pokrajine in prebivalstev $\mathrm{v}$ preteklosti nismo pripisovali nobenega posebnega, kaj šele izjemnega, pomena (slika 1). Zaradi svojevrstne, predvsem logistično-gradbeniške in urbanistične, logike umeščanja infrastruktur $\mathrm{v}$ prostor smo spoznali, da je atraktorjev $\mathrm{v}$ prostoru, ki so vedno znova privabljali poseljevanje, veliko več. Med slednjimi lahko postavimo 
tudi Zavrč - dolgotrajno arheološko najdišče, na katerem je bilo pod cesto, ki vodi k mejnemu prehodu med Zavrčem in Dubravo Križovljansko, odkrito tudi poznobronastodobno grobišče (sliki 1 in 2). Žgani grobovi in ostanki naselbine iz bronaste dobe so bili odkriti pod številnimi plastmi rimskodobne in srednjeveške poselitve ter cestne infrastrukture, v preteklosti večkrat trasirane natančno pod sedanjo (Lubšina Tušek 2008; 2010).

Razprava se bo osredotočila na nekatere možnosti interpretacije najdišča Zavrč v smislu kontinuitete uporabe prostora, povezane $s$ »konceptom smrti« pozne bronaste dobe severovzhodne Slovenije.

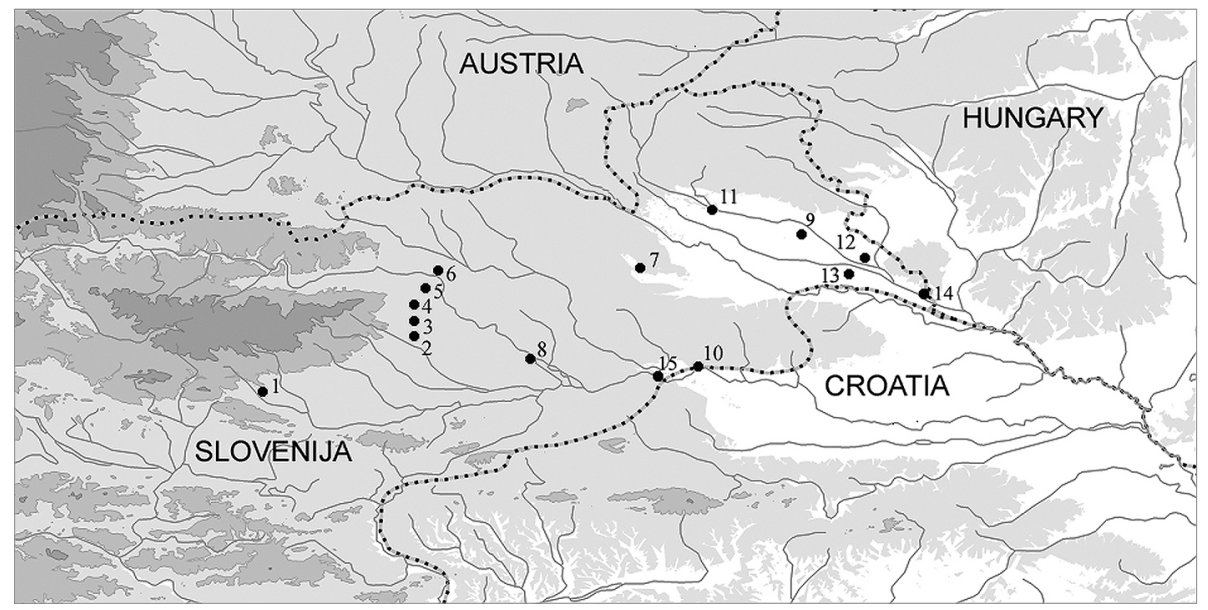

Slika i. Najpomembnejša najdišča pozne bronaste dobe v severovzhodni Sloveniji (I Brinjeva gora, 2 Slivnica, 3 Spodnje Hoče, 4 Rogoza, 5 Pobrežje, 5 Malečnik in Meljski hrib, 7 Sodolek, 8 Ptuj, 9 Gorice pri Turnišču, Io Ormož, II Pod Kotom-sever, Kotare-baza in Nova tabla, I2 Pri Muri, I3 Oloris, I4 Pince, is Zavrč (po Lubšina Tušek, Kavur in Blečić Kavur 2014, 74, Fig. 3).

\section{Obrazci in dinamika uporabe prostora}

Grobišče v Zavrču ne predstavlja posebnosti zgolj zaradi številčnosti odkritih grobov in bogastva posameznih, ampak je priča o izjemno dolgotrajni vpetosti lokacije $\mathrm{v}$ mentalne obrazce prostora bronastodobne (in starejšeželeznodobne) družbe (slika 2). Analize materialne kulture, predvsem oblik in okrasa keramičnega posodja, nam ponujajo, zaradi dolgotrajnega pokopavanja na grobišču, možnost vpogleda v kulturne spremembe $\mathrm{v}$ času celotnega trajanja pozne bronaste dobe oziroma kulture žarnih 


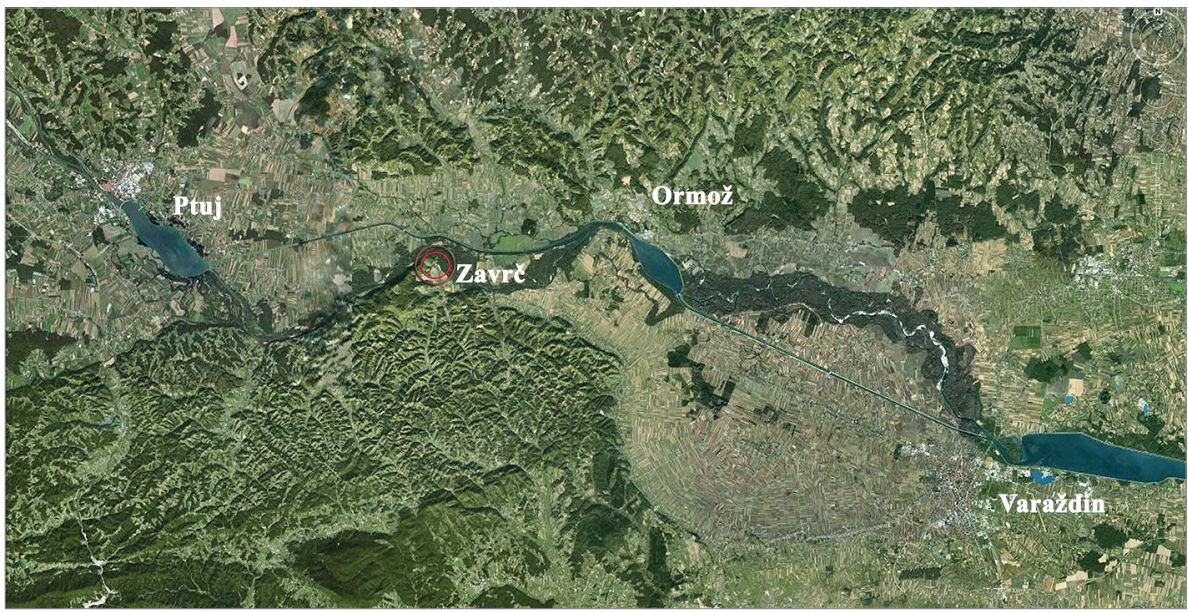

Slika 2. Geografska lega Zavrča na širšem območju Ptuj - Ormož - Varaždin (po Lubšina Tušek, Kavur in Blečić Kavur 2014, 73, Fig. 2).

grobišč med koncem 15. in 10. stoletjem pr. n. št. na prostoru južnega roba Podravja (Lubšina Tušek, Blečić Kavur in Kavur 2014; Blečić Kavur, Kavur in Lubšina Tušek 2018). Obravnavane v lokalni kot tudi globalni perspektivi nam pričajo o pretoku idej, znanj in blaga, ki je omrežene družbe povezoval z najnovejšimi slogovnimi in tehnološkimi odkritji tedanjega sveta. Zaradi spremenljivosti same materialne kulture kot tudi obredov pokopov na grobišču se odpirajo možnosti za razumevanje predvsem družbenih dinamik tega izjemnega časa $\mathrm{v}$ človeški preteklosti.

Številni arheološki ostanki, odkriti na omejenem prostoru, so v preteklosti velikokrat predstavljali težave pri tradicionalnih arheoloških interpretacijah. Težko je bilo razločiti med dolgotrajno poselitvijo prostora in vedno vnovičnim vračanjem na isto mesto, ki je zlilo ostanke mnogih kratkotrajnih obdobij dejavnosti. Za kulturnozgodovinsko interpretacijo bi to pomenilo, da lahko v primeru kontinuirane poselitve opazujemo notranjo kulturno evolucijo (materialne) kulture predniških in skupnosti potomcev. V primeru vnovične poselitve pa smo soočeni zgolj z nepovezanimi izseki iz kulturnih procesov, za katere domnevamo vzročno povezanost. Upoštevajoč količino arheoloških podatkov kot tudi metodologijo arheološkega dela lahko slednje le s težavo, kljub trditvam, dokažemo. Vsaj na naselbinah nam natančna izkopavanja, podprta $\mathrm{z}$ analizami materialne kulture in absolutnimi datacijami, omogočajo prepoznavo ter pojasnitev 
časovne in prostorske dinamike posameznih obdobij poselitve. Grobišča pa imajo povsem drugačno perspektivo!

Kako misliti kontinuiteto? Prav poznobronastodobno grobišče v Zavrču ponuja nekaj odgovorov na to vprašanje (slika 2). Če se je na prvi pogled zdelo, da je število grobov dokaj veliko, saj gre za enega izmed večjih grobišč, odkritih na prostoru severovzhodne Slovenije (slika 1), smo po preudarku, upoštevajoč dolžino trajanja pokopavanja, vzajemno s preliminarnimi analizami kronologije pokopavanja, morali priznati, da je iz vsakega obdobja prisotnih zgolj manjše število grobov. Povrh vsega ni mogoče določiti v prostoru časovno omejenih skupin grobov, ampak so bili ti naključno raztreseni po celotnem prostoru grobišča. Očitno so tukaj svoje pokojnike pokopaval generacije, za katere je bil ta prostor zelo poseben. Zagotovo je predstavljal pomembno geografsko lego prehoda, kjer se je iz predalpskih dolin pogled razširil $\mathrm{v}$ panonsko ravnico, prehoda, preko katerega so se novosti iz vseh smeri »bronastodobnega sveta" prepletale in posledično spreminjale lokalne skupnosti tega dela Podravja (Lubšina Tušek, Kavur in Blečić Kavur 2014; slika 2). Zdi se, da grobišče v Zavrču ni pokopališče lokalne skupnosti, na katerem so končali vsi pokojniki. Tako izjemno bogati kot tudi izjemno revni grobovi v različnih obdobjih pričajo, da so bili tukaj pokopani le redki izbranci. Gre namreč za skrbno izbrane predstavnike družbe ali družb, ki so na ideološki ravni lastninile prostor, v katerega so namensko umeščale svoje člane, deležne novih oblik in odrazov njihovih identitet. Na ta način je družba živih konstituirala skupnost mrtvih na izrazitem kraju in $\mathrm{v}$ izjemnem prostoru.

\section{O konceptu smrti}

Vpeljava »koncepta smrti« kot zgodovinskega subjekta v arheološke analize je ponovno vzbudila interes za preučevanje »konca življenja« (Harke 1997; Nilsson Stutz 2014). Kljub obsežni literaturi o načinih uporabe podatkov o pokopih z namenom, da bi se dokopali interpretacij družbenih in kulturnih okvirov preteklih populacij, razumevanje pokopavanja temelji na sistematizaciji podatkov ter vrednotenju sprememb v prostoru in času. Tako so se $\mathrm{v}$ zadnjih dvajsetih letih raziskovalci osredotočali predvsem na preučevanje »izstopajočih" grobov - to je tistih, s pomočjo katerih so lahko na podlagi redkih ali številnih pridatkov materialne kulture predpostavljali poseben družbeni status pokojnika. Pozornosti so bili deležni t. i. »deviantni« pokopi, ki so se v bistvu razlikovali po drugačni manipulaciji s pokojniki in z grobnimi pridatki. Slednje pomeni, da so bili posamezni- 
ki pokopani na način, ki se ni skladal z uveljavljeno normo iz obdobja ali pa preučevane družbene strukture. Angažiranost raziskovalcev je posledično težila k monumentalnosti, a deviantnost, na spodnjem robu lestvice identifikacije, je spodbudila veliko manj pozora. Analize pokopov, grobnih pridatkov, obredov in človeških skeletnih ostankov ne nudijo pomembnih informacij samo o naravi družbenih, ekonomskih, političnih in, širše, kulturnih statusov preminulih $\mathrm{v}$ času njihovega življenja, ampak veliko več. Konec koncev mrtvi ne pokopavajo sebe, temveč je smrt simbol živih, ki $\mathrm{v}$ določenem protokolu redefinirajo obstoječe in konsolidirajo nove družbene prakse (Fahlander in Østigaard 2008; Insoll 2011; Nilsson Stutz 2010; 2014).

Prav zato izstopajoči načini manipulacije s pokojniki ali pridatki, povezani s kompleksnim razponom različnih družbenih in religioznih prepričanj, pričajo o odločitvah živih in ni nujno, da so v linearni povezavi s statusom pokojnikov za časa življenja (Nilsson Stutz 2008; 2010). Zato jih je potrebno opazovati kot del norme skupaj $\mathrm{z}$ »normalnimi« pokopi in ne izolirano, kar pomeni da niso zgolj bogati, ampak so vsi grobovi dosežek pozitivne selekcije, s katero želijo živi definirati status pokojnikov (Oestigaard in Goldhahn 2006; Knappett 2011; Insoll 2011). Pri tem je tudi prostorska umeščenost grobov del namenske konstrukcije identitete. Tako dolgotrajno pokopavanje $\mathrm{v}$ Zavrču ni samo posledica ustaljenega prebivanja stabilne družbe v neposredni bližini, ampak je posledica vztrajnega prepričanja, da je potrebno pokojnike vedno znova pokopavati na prehodu nad reko Dravo (slika 2). Odkrito grobišče predstavlja drugačno sliko kot večina drugih na prostoru severovzhodne Slovenije (slika 1) in severozahodne Hrvaške. V kronološkem smislu je izjemno zaradi prisotnosti grobov iz starejše in mlajše faze kulture žarnih grobišč in zaradi dejstva, da najmlajši pokopi grobišča sodijo že v sam začetek starejše železne dobe. Ekstravagantnost završkih grobov se odraža $\mathrm{v}$ kulturnozgodovinskem pogledu, predvsem zaradi odstopajočih praks pokopavanja ter kvalitete in kvantitete grobnih pridatkov v posameznih obdobjih.

Na samem začetku pokopavanja so kulturne povezave, kot so jih odražale oblike keramičnih posod in ritual pokopa, izkazovale neposredne podobnosti s kulturnimi značilnostmi skupnosti na južneje ležečem medrečju Save in Drave, severozahodne Hrvaške. Prepoznavne so po uvedbi t. i. kulturnega fenomena sežiganj pokojnikov in njihovih pokopov v žarah, v arheološki literaturi opredeljenih z enotnim pojmom skupina Virovitica zgodnje kulture žarnih grobišč (Vinski-Gasparini 1973; 1983; Ložnjak Dizdar 
2011; 2014). Vzporedno z dokajšnjo uniformnostjo, obravnavano znotraj širših nadregionalnih formalnih trendov, je bilo izpostavljeno tudi oblikovanje keramičnih posod oziroma posebnosti, ki se pojavljajo na omejenem prostoru severovzhodne Slovenije, primarno kot odraz številnih identitet pokojnikov (Lubšina Tušek, Blečić Kavur in Kavur 2014; Blečić Kavur, Kavur in Lubšina Tušek 2018; slika 3).

$\mathrm{V}$ poznem delu starejše kulture žarnih grobišč se pojavijo nadregionalno veliko bolj razširjeni, pa vendar v celosti materialne kulture v manjši meri zastopani skupni trendi, kar sicer lahko interpretiramo kot širitev omrežij, pa vendar širitev skupnih kulturnih imenovalcev. Tako zraven podobnosti s keramiko zagrebške skupine lahko razložimo tudi oblike, ki jih poznamo od zahodne Panonije v širšem smislu pojmovanja pa vse do osrednje Slovenije in predalpskega prostora. Tudi druga grobišča v regiji, ki so se začela $\mathrm{v}$ Bd D, so ostala $\mathrm{v}$ uporabi do horizonta $\mathrm{Ha} \mathrm{A}$, ko so nastopili novi oblikovni elementi (Dular 2002, 204-206). Nato so se pokopavanja na teh grobiščih večinoma zaključila. V Zavrču pa mlajši grobovi starejše faze kulture žarnih grobišč izkazujejo na eni strani fragmentacijo nekdaj povezujočega kulturnega fenomena in po drugi strani začetke procesov izoblikovanj lokalnih (tehnoloških) tradicij v okviru širših kulturnih pojavov (Blečić Kavur, Kavur in Lubšina Tušek 2014, 77-78; slika 3).

\section{Obredne prakse pokopa kot identitete družb v regiji}

Znotraj tega procesa lahko $\mathrm{z}$ analizo grobov opazujemo procese sprememb statusa grobišča v okviru tvorbe lokalnih identitet, ki jih na prostoru med dravsko dolino in Ptujskim poljem že več kot stoletje poznamo kot ruško skupino kulture žarnih grobišč. Pravzaprav bi lahko 11. stoletje pr. n. št. okvirno določili kot obdobje začetka pokopavanja na klasičnih grobiščih te skupine, pri čemer so najstarejši grobovi na slednjih dokaj redki (Pahič 1972, Tab. 8, 17-18; Pare 1998, 343; Teržan 1999, 113; Črešnar 2011, 64). Spremembam poselitvenih vzorcev, mobilnosti populacij v regiji in gospodarstva, opazovani na naselbinah (Črešnar 2010, 72-73; 2011, 64-65) in delno odraženi v strukturi in sestavi depojskih najdb (Teržan 1999, 120), so sledile spremembe v »industriji« bronastih predmetov, kjer so alpski broni prevladali nad karpatskimi (Trampuž Orel, Klemenc in Hudnik 1993, 165; Trampuž Orel 1999, 415-419). Slednje lahko razumemo ne zgolj kot menjavo tehnologij, ampak predvsem kot spremembe omrežij trgovine na dolge razdalje in oskrbovanja s ustreznimi surovinami. 

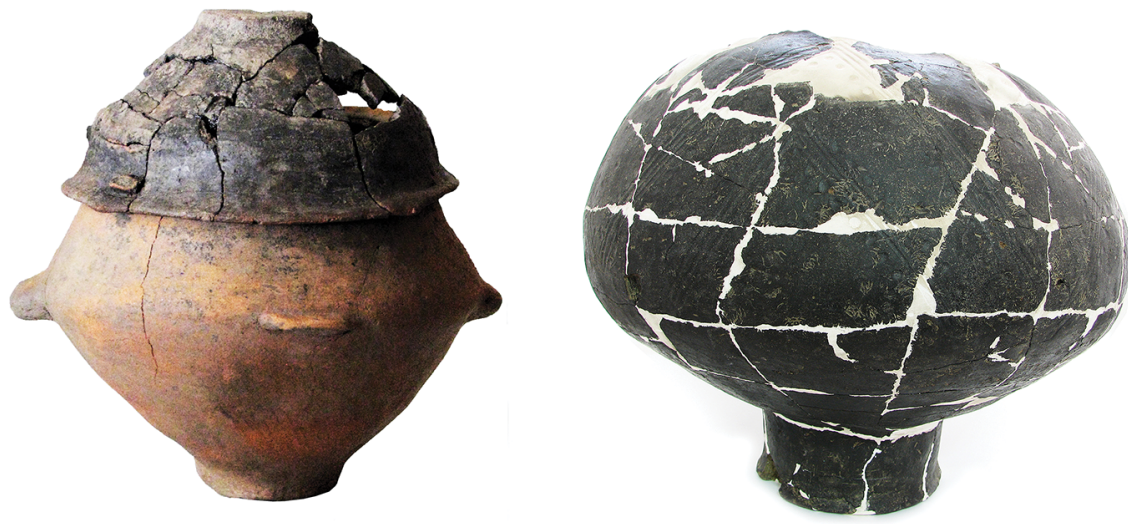

Slika 3. Żari iz grobov 49 in 52 iz grobišča v Zavrču (po Lubšina Tušek, Kavur in Blečić Kavur 2014, 77-78, Fig. 6-7).

Sklenemo lahko, da so se največje spremembe v regiji odvile na koncu stopnje Ha A1, ko so se nehala pokopavanja na manjših in se začela na večjih grobiščih. Na Zavrču pa se je pokopavanje nadaljevalo - kar nekaj grobov lahko pripišemo temu obdobju. Še več, gre za najbogatejše odkrite grobove tako na grobišču kot tudi $\mathrm{v}$ regiji. $\mathrm{V}$ nasprotju $\mathrm{z}$ vsesplošnim vzorcem je količina bronastih predmetov $\mathrm{v}$ nekaterih grobovih izjemna, še predvsem zato, ker je bilo v moških grobovih odkrito orožje ter v ženskih bogata noša in nakit. Prav tako lahko opazujemo kompleksne obrede pokopa, ki niso bili prepoznani na drugih grobiščih. Povrh vsega pa so bile ugotovljene tudi prakse namenskega uničevanja, fragmentacije in selektivne depozicije predmetov. Gre za prakse, ki smo jih doslej poznali zgolj iz grobov v Mariboru, v katerih je prav tako bilo odkrito uničeno orožje (Müller-Karpe 1959, T. 118; Pahič 1968, 24, sl. 4).

$\mathrm{Z}$ nastankom mlajše faze kultur žarnih grobišč se $\mathrm{v}$ regiji začne intenzivnejše pokopavanje na večini večjih (npr. Ruše, Maribor, Brinjeva gora, Hajdina, Pobrežje) in manjših (npr. Ruše, Ptuj-Rabelčja vas, Ormož) grobišč, vključenih v ruško skupino (Teržan 1995; 1999) (slika 1). Pokopavanje v Zavrču pa se je še kar nadaljevalo - vendar na drugačen način. Na vseh grobiščih se je povečevala količina keramičnih pridatkov $\mathrm{v}$ grobovih in vzporedno tudi velikost posod, predvsem žar. V Zavrču pa tovrsten trend ni bil prepoznan. Da bi pojasnili ta regionalno deviantni fenomen, ne moramo zgolj domnevati, da je geografska lega grobišča predstavljala poglaviten dejavnik za kontinuiteto pokopavanja. 


\section{Zaključek}

Z opazovanjem točk v topografiji prostora, kot da bi bile slednje odraz preteklih družbenih sistemov, pridemo do teme gibanja v prazgodovini. Gibanje v bistvu zadeva odnose med časom, predmeti, osebami in prostorom. Pri tem se izpostavlja omrežena narava ljudi in predmetov s posebnim fokusom na časovnost kot odraz prekrivajočih se tokov trajanja. Razumevanje gibanja $\mathrm{v}$ preteklosti zahteva odmik od tradicionalnih, na terenskih raziskavah temelječim arheoloških ontologij proti fluidnim, na transmisijah in pogajanjih temelječih študijam (Tilley 1997; Barrett 1999; Knappett 2011; Harmanşah 2014). Arheologija po svoji naravi razvrsti predmete, dobesedno zamrznjene $\mathrm{v}$ prostoru, $\mathrm{v}$ tridimenzionalne matrice, $\mathrm{v}$ najdišča, iz katerih so bili odstranjeni ljudje. Arheologija gibanja pa se odmika od statičnosti in ustvarja nove poti, ki sledijo prestopom meja kontekstualno neločljivo v mobilnosti predmetov in ljudi (Tilley 1999; Knappett 2011). Ta odmik od tradicije zahteva recepcijo kontradikcije, kratkotrajne sledi in bežne odnose, ki so jih $\mathrm{v}$ gibanju zapustili ljudje in stvari. Novi pristopi k mobilnosti tudi postavljajo visoko stopnjo fleksibilnosti in kreativnosti, predvsem pa zahtevajo razumevanje konceptov družbenih (pod)elit - tistih, ki niso bile zgolj mobilne, ampak so imele moč kontrole, reduciranja in stimuliranja mobilnost (ljudi in predmetov) kot tudi prenehanja teh mobilnosti oziroma njihovo vključitev $\mathrm{v}$ grobove in depojske najdbe.

Tako razumevanje bi lahko pojasnilo »kontinuiteto « pokopavanj kot tudi spreminjanje strukture, kvantitativno kot kvalitativno, grobnih pridatkov v grobovih Zavrča. Seveda je tovrstna interpretacija enostavna v primeru, ko opazujemo bogate grobove $\mathrm{z}$ bronastim nakitom in orožjem, ki jih $\mathrm{v}$ populistični arheološki retoriki imenujemo pokopi družbene elite. $\mathrm{V}$ preteklosti so bili razlogi za oblikovanje družbenih elit razlagani z akumulacijo bogastva ali kontrolo nad proizvodnjo oziroma s kombinacijo obeh. Kasneje so bili dodani še koncepti kontrole nad trgovino na dolge razdalje in redistribucijo luksuznih/prestižnih predmetov. Več dejavnikov kot je bilo dodajanih, neprepričljivejše so postajale razlage, iskanje enega samega vzroka pa manj verjetno. Enovzročne razlage teh procesov so torej zastarele, zato moramo dejavnike, ki so povzročili te dogodke, obravnavati na več različnih nivojih. Procesi demografskih, ekonomskih in družbenih sprememb so bili verjetno posledica klimatskih in tehnoloških sprememb, ki so pospešile spremembe skupnosti v dinamičnih stanjih ponovnih vzpostavitev družbenih struktur zaradi tehnoloških inovacij in sprememb verskih/ slogovnih dojemanj sveta. V skladu s funkcionalistično teorijo sociologije 
najverjetneje tudi takrat ni obstajala samo ena sama elita, manjšina izbranih na eni in večina ostalih na drugi strani, problematiziran je tudi obstoj vladajočega razreda v piramidalni shemi (Hartman 2007, 37-39). Družba je bila tudi v preteklosti sestavljena iz več različnih (pod)elit, ki včasih tekmujejo za vire oziroma prestiž na istih nivojih, včasih pa delujejo popolnoma vzporedno. Zato so prav družbe živih, in njihove podelite, definirale, izvajale in kontrolirale vse družbene prakse, vključno s protokolom pokopavanja in nadzora nad skupnostmi mrtvih.

Pokopavanje pokojnih članov družbe z določenim družbenim in ekonomskim statusom, kot tudi spremljajoči obredi in odloženi predmeti, so bili dodatno nabiti s simbolizmom. Njihovo prepoznavanje je na materialnem nivoju enostaven postopek, znotraj katerega percepcija predmetov sproži aktivacijo različnih kognitivnih procesov, ki jih vodi predvsem predhodno pridobljeno znanje o teh specifičnih predmetih. Te podatke so posredovali skozi kulturno konstruirane dejavnosti, ki so vsebovale oblikovanje obligacijskih razmerij med udeleženci v produkcijskih ciklusih ter, najpomembneje, znotraj omrežij trgovine na dolge razdalje. Poglavitne točke teh dejavnosti, osi, okoli katerih so se vrtela družbena razmerja, pa so bili pokopi in depojske najdbe - s simbolizmom nabite družbene prakse. Tako so v obredih javnega razkazovanja predmetov kot tudi dejanj živi obligacijska razmerja opredelili v prostoru in času (Nilsson Stutz 2008; 2010). Grobovi v Zavrču so prav to - posledica dolgotrajnih procesov pogajanj o medsebojnih odnosih med družbenimi (pod)elitami v regiji.

$\mathrm{V}$ nasprotju s tradicionalnimi kulturno-zgodovinskimi metodologijami interpretacij, ki so variabilnost materialne kulture razlagale kot velik skupek ločenih lokalnih enot (identitet/kultur/skupin/entitet), lahko razmerja med spremembami in kontinuiteto na opazovanem najdišču razlagamo kot znak vztrajno spreminjajočega se in medsebojno povezanega sveta (pod)elit poznobronastodobnih družb. V tej perspektivi moramo življenje in delovanje $\mathrm{v}$ preteklosti opazovati, kot da ga je oblikoval sistem oziroma sistemi odnosov - tako družbenih kot okolijskih. Tako življenja in smrt posameznikov (grobovi) ali dialektičnih posameznikov (depojske najdbe) na podlagi arheoloških analiz opazujemo kot metaforična, vzročna in interaktivna (Tilley 1999). Gre za dejstvo, da je bilo učenje kulture ter družbenih vlog, to je pridobivanje idej, podob, zgodb, habitov in struktur odnosov, prilagodljivo, da bi lahko dosegalo svoje cilje, zlasti obnavljalo obstoječe stanje brez večjih sprememb. Zato, ker je življenje ob meji vedno bilo nevarno in težko, lahko spremembe v sestavah materialne kulture 
v grobovih Zavrča razumemo kot posledico družbenih sprememb, ki pa na podsistemski ravni niso bile tako skrajne, da bi spremenile sistem percepcije delovanja družb v prostoru. $\mathrm{Z}$ drugimi besedami, če so se kontinuitete pokopavanja na drugih grobiščih spreminjale, se na Zavrču niso; če so se sestavi pridatkov na drugih grobiščih v regiji spreminjali, so se na Zavrču spreminjali drugače - družbe živih so na Zavrču sestavljale drugačno skupnost mrtvih.

\section{Zahvala}

Pri nastanku te raziskave sta mi z zbiranjem različne dokumentacije, $\mathrm{s}$ številnimi razpravami in koristnimi predlogi nesebično pomagala Boris Kavur in Marija Lubšina Tušek, za kar se jima iskreno zahvaljujem.

Prispevek je nastal na podlagi raziskav, sofinanciranih iz projekta ARRS J6-9363 »Skupnosti mrtvih, družbe živih. Pozna bronasta doba vzhodne Slovenije«.

\section{Literatura}

Barrett, J. 1999. "Chronologies of landscapes." V The Archaeology and Anthropology of Landscape. Shaping your Landscape, ur. P. J. Ucko in R. Layton, 21-30. London; New York: Routledge.

Blečić Kavur, M., B. Kavur in M. Lubšina Tušek 2018. „Sinhronost - značajna slučajnost pozne bronaste dobe." V Srečanja in vplivi v raziskovanju bronaste in železne dobe na Slovenskem, ur. M. Črešnar in M. Vinazza, 187-197. Ljubljana: Znanstvena založba Filozofske fakultete Univerze v Ljubljani.

Črešnar, M. 2009. »Radiokarbonsko datiranje bronaste in starejše železne dobe - slovenska perspektiva.« Arheo 26: 33-51.

Črešnar, M. 2010. »New Research on the Urnfield period of Eastern Slovenia: A Case Study of Rogoza near Maribor.« Arheološki vestnik 61: 7-119.

Črešnar, M. 2011. "New Aspects on the Ha A Phase in Eastern Slovenia.« V Beiträge zur Mittel- und Spätbronzezeit sowie zur Urnenfelderzeit am Rande der Südostalpen. Internationale Archäologie 15, ur. C. Gutjahr in G. Tiefengraber, 37-50. Rahden, Westfalen: Marie Leidorf.

Dular, J. 2002. "Dolnji Lakoš in mlajša bronasta doba med Muro in Savo.« V J. Dular, I. Šavel in S. Tecco Hvala, Bronastodobno naselje Oloris pri Dolnjem Lakošu, Opera Instituti archaeologici Sloveniae 5, 143-228. Ljubljana: Založba Znanstvenoraziskovalnega centra. 
Fahlander, F., in T. Østigaard 2008. »The Materiality of Death: Bodies, Burial, Beliefs." V The Materiality of Death: Bodies, Burial, Beliefs, British Archaeological Reports International Series 1768, ur. F. Fahlander in T. Østigaard, 1-16. Oxford: Archeopress.

Harke, H. 1997. "The Nature of Burial Data." V Burial and Society: The Chronological and Social Analysis of Archaeological Burial Data, ur. C. Kjeld Jensen in K. Høilund Nielsen, 19-26. Aarhus: Aarhus University Press.

Harmanşah, Ö. 2014. »Introduction: Towards an Archaeology of Place.« V Of Rocks and Water: Towards an Archaeology of Place, ur. Ö. Harmanşah, 1-12. Oxford; Philadelphia, PA: Oxbow Books.

Hartman, M. 2007. The Sociology of Elites. London; New York: Routledge.

Insoll, T. 2011, ur. The Oxford Handbook of the Archaeology of Ritual and Religion. Oxford: Oxford University Press.

Kavur, B. 2007. »Middle to Late Bronze Age in Eastern Slovenia: The Highways to Archaeological Knowledge.«V Studien zur Mittel- und Spätbronzezeit am Rande der Südostalpen, Universitätsforschungen zur Prähistorischen Archäologie 148, ur. G. Tiefengraber, 51-65. Bonn: Rudolf Habelt GMBH.

Kavur, B. 2011. "This Is How We Do It." V Beiträge zur Mittel- und Spätbronzezeit sowie zur Urnenfelderzeit am Rande der Südostalpen. Internationale Archäologie 15, ur. C. Gutjahr in G. Tiefengraber, 81-88. Rahden, Westfalen: Marie Leidorf.

Kavur, B. 2012. »Sodolek - Just Another Site from the Middle/Late Bronze Age Boundry." Prilozi instituta za arheologiju u Zagrebu 29: 71-88.

Kerman, B. 2011. »Die spätbronzezeitliche Siedlung Pod Grunti - Pince (Slowenien).« V Beiträge zur Mittel- und Spätbronzezeit sowie zur Urnenfelderzeit am Rande der Südostalpen, Internationale Archäologie 15, ur. C. Gutjahr in G. Tiefengraber, 89-100. Rahden, Westfalen: Marie Leidorf.

Knappett, C. 2011. An Archaeology of Interaction: Network Perspectives on Material Culture \& Society. Oxford: Oxford University Press.

Ložnjak Dizdar, D. 2011. „Starija faza kulture polja sa žarama u Sjevernoj Hrvatskoj - novi izazovi.« V Starija faza kulture polja sa žarama $u$ Sjevernoj Hrvatskoj - novi izazovi, ur. M. Dizdar, D. Ložnjak Dizdar in S. Mihelić, 12-35. Osijek: Arheološki muzej Osijek, Arheološki muzej Zagreb.

Ložnjak Dizdar, D. 2014. »South-Eastern Periphery of the Urnfield Culture? The Croatian Perspective: Northern Croatia at the crossroads at the be- 
ginning of the Urnfield culture."V The Beginning of the Late Bronze Age between the Southern Alps and the Danube: Proceedings of the International Conference in Osijek, October 20-22, 2011, Serta Instituti Archaeologici 1, ur. D. Ložnjak Dizdar in M. Dizdar, 235-247. Zagreb: Institut za arheologiju.

Lubšina Tušek, M. 2008. »Zavrč." Varstvo spomenikov 44: 309-312.

Lubšina Tušek, M. 2010. "Zavrč." Varstvo spomenikov 46: 412-414.

Lubšina Tušek, M., B. Kavur in M. Blečić Kavur 2014. »In to the Great Wide Open."V The Beginning of the Late Bronze Age between the Southern Alps and the Danube: Proceedings of the International Conference in Osijek, October 20-22, 2011, Serta Instituti Archaeologici 1, ur. D. Ložnjak Dizdar in M. Dizdar, 125-135. Zagreb: Institut za arheologiju.

Müller-Karpe, H. 1959. Beiträge zur Chronologie der Urnenfelderzeit nördlich und südlich der Alpen. Römisch-germanische Forschungen 22. Berlin: De Gruyter.

Nilsson Stutz, L. 2008. "More than Metaphor: Approaching the Human Cadaver in Archaeology." V The Materiality of Death: Bodies, Burials, Beliefs, British Archaeological Reports International Series 1768, ur. F. Fahlander in T. Østigaard, 19-28. Oxford: Archaeopress.

Nilsson Stutz, L. 2010. »The Way We Bury Our Dead. Reflections on Ritual Practice and Community at the Time of the Mesolithic - Neolithic Transition." Documenta Praehistorica 37: 33-42.

Nilsson Stutz, L. 2014. »A Proper Burial.» V Death and Changing Rituals: Function and Meaning in Ancient Funerary Practices, ur. J. Rasmus Brandt, M. Prusac in H. Roland, 1-16. Oxford, Philadelphia, PA: Oxbow Books.

Nilsson Stutz, L. 2016. »Building Bridges between Burial Archaeology and the Archaeology of Death."Current Swedish Archaeology 24: 12-35.

Oestigaard, T., in J. Goldhahn 2006. „From the Dead to the Living: Death as Transaction and Re-Negotiations."Norwegian Archaeological Review 39 (1): $27-48$.

Pahič, S. 1968. "Maribor v prazgodovini.« Časopis za zgodovino in narodopisje 39 (4): 9-63.

Pahič, S. 1972. Pobrežje. Katalogi in monografije 6. Ljubljana: Narodni muzej Slovenije.

Pare, C. 1998. »Beiträge zum Übergang von der Bronze- zur Eisenzeit in Mitteleuropa. Teil I: Grundzüge der Chronologie im östlichen 
Mitteleuropa (11. -8. Jahrhundert v. Chr.).« Jahrbuch des RömischGermanischen Zentralmuseums Mainz 45: 293-433.

Teržan, B. 1995. "Stand und Aufgaben der Forschungen zur Urnenfelderzeit in Jugoslawien." V Beiträge zur Urnenfelderzeit nördlich und südlich der Alpen, Ergebnisse eines Kolloquiums, Monographien des RömischGermanischen Zentralmuseum 35, ur. M. zu Erbach, 323-372. Bonn: Habelt

Teržan, B. 1999. "An Outline of the Urnfield Culture Period in Slovenia.« Arheološki vestnik 50: 97-143.

Teržan, B. in M. Črešnar 2014a. Absolutno datiranje bronaste in železne dobe na Slovenskem. Katalogi in monografije 40. Ljubljana: Narodni muzej Slovenije.

Teržan, B. in M. Črešnar 2014b, „Absolutno datiranje bronaste dobe na Slovenskem.« V Absolutno datiranje bronaste in železne dobe na Slovenskem, Katalogi in monografije 40, ur. B. Teržan in M. Črešnar, 661702. Ljubljana: Narodni muzej Slovenije.

Tilley, C. 1997. A Phenomenology of Landscape: Places, Paths and Monuments. Oxford: Berg Publishers.

Tilley, C. 1999. Metaphor and Material Culture. Oxford: Blackwell.

Trampuž Orel, N. 1999. "Archeometallurgic Investigations in Slovenia: A History of Research on Non-Ferrous Metals."Arheološki vestnik 50: 407-429.

Trampuž Orel, N., S. Klemenc in V. Hudnik 1993. »Spektrometrične raziskave poznobronastodobnih depojskih najdb Pušenci, Cerovec in Hudinja.« V Ptujski arheološki zbornik ob 1oo-letnici muzeja in Muzejskega društva, ur. B. Lamut, 159-170. Ptuj: Pokrajinski muzej Ptuj.

Vinski-Gasparini, K. 1973. Kultura polja sa žarama u sjevernoj Hrvatskoj. Monografije 1. Zadar: Filozofski fakultet.

Vinski-Gasparini, K. 1983. »Kultura polja sa žarama sa svojim grupama.« V Praistorija Jugoslavenskih zemalja IV - Bronzano doba, ur. A. Benac, 547667. Sarajevo: Akademija nauka i umjetnosti Bosne i Hercegovine, Centar za balkanološka ispitivanja. 


\section{Summary}

Life on the border is dangerous and hard

Communities of the Dead, Societies of the Living: The Late Bronze

Age cemetery in Zavrč

Zavrč is a long-lasting archaeological site, where a Late Bronze Age cemetery was discovered under the road leading to the border crossing between Zavrč and Dubrava Križovljanska. It is not unique among the Late Bronze Age cemeteries solely because of the number of uncovered graves and the richness of several burials, but also due to the long period during which people were buried there. It is a testament to the extraordinary long-lasting temporal integration of the location into the mental patterns and special perception of the Late Bronze Age (and Early Iron Age) societies in the region. Due to the variability of material culture itself, as well as burial rites and the concept of death, considered in a local as well as a global perspective, the cemetery opens up opportunities to understand the social dynamics of this extraordinary time in the human past. Therefore, changes in the composition of material culture in the graves of Zavrč can be understood as reflections of social changes, which at the subsystem level were not so influentially powerful to change the system, but still enough to create a variability within the uniform perception of the functioning of societies in space. In other words, if the continuities of burial in other cemeteries changed, they did not change in Zavrč, if the composition of grave goods in other cemeteries in the region changed, they changed differently in Zavrč - societies of the living created different "concept of death" in the Zavrč community of the dead. 